\title{
The Quest for Identity in Adolescence: Heterogeneity in Daily Identity Formation and Psychosocial Adjustment Across 5 Years
}

\author{
Andrik I. Becht \\ Utrecht University \\ Susan J. T. Branje and Wilma A. M. Vollebergh
Utrecht University
}

\author{
Jaap J. A. Denissen \\ Tilburg University
}

\author{
Stefanie A. Nelemans \\ Utrecht University and Katholieke Universiteit Leuven
}

\author{
Hans M. Koot \\ VU University Amsterdam and EMGO Institute for Health \\ and Care Research
}

Wim H. J. Meeus

Utrecht University and Tilburg University

\begin{abstract}
Identity formation is one of the key developmental tasks in adolescence. According to Erikson (1968) experiencing identity uncertainty is normative in adolescence. However, empirical studies investigating identity uncertainty on a daily basis are lacking. Hence, studying individual differences in daily certainty (i.e., identity commitment levels) and uncertainty (i.e., identity commitment fluctuations and identity reconsideration) in the identity formation process may advance our knowledge about the extent to which adolescents' identity uncertainty is part of normative identity development. Therefore, this longitudinal study examined heterogeneity in certainty and uncertainty dynamics of adolescents' daily identity formation using a longitudinal microlevel approach. Dutch adolescents $\left(N=494 ; M_{\text {age }}=13.03\right.$ years at $\mathrm{T} 1 ; 56.7 \%$ boys) reported on 2 key dimensions of identity formation (i.e., commitment and reconsideration) in both the educational and interpersonal domain on a daily basis for 3 weeks within 1 year, across 5 successive years. Multivariate latent class growth analyses suggested both in the educational and interpersonal identity domain a class of adolescents displaying a "crisis-like" identity formation process, and an "identity synthesis" class. Classes revealed differential development of (global and school) anxiety, aggression, and best friend support. Taken together, the present study confirmed Erikson's notion that experiencing daily identity uncertainty is common during adolescence. However, a substantial amount of adolescents also showed a process toward identity maturation already during adolescence.
\end{abstract}

Keywords: identity development, certainty/uncertainty dynamics, adolescence, psychosocial adjustment, daily diary method

An important developmental task of adolescence is the formation of a certain identity (Erikson, 1968). Adolescents need to develop strong commitments across different life domains, after having explored several alternatives (Marcia, 1966). A number of identity models point out that the process of identity formation represents a dynamic between certainty/synthesis and uncertainty/ confusion (Crocetti, Rubini, \& Meeus, 2008; Erikson, 1968, 1968; Luyckx, Goossens, \& Soenens, 2006; Meeus, Van de Schoot,
Keijsers, Schwartz, \& Branje, 2010). As this process takes place on a daily basis (Bosma \& Kunnen, 2001; Lichtwarck-Aschoff, Van Geert, Bosma, \& Kunnen, 2008), it is important to study the daily dynamics of identity formation (Lichtwarck-Aschoff et al., 2008). While a limited number of longitudinal studies investigated identity formation across adolescence (Kroger, Martinussen, \& Marcia, 2010; Meeus, 2011), no longitudinal studies have been conducted into daily identity development across adolescence.
Andrik I. Becht, Research Centre Adolescent Development, Utrecht University; Stefanie A. Nelemans, Department of Adolescent Development, Utrecht University, and Department of School Psychology and Child and Adolescent Development, Katholieke Universiteit Leuven; Susan J. T. Branje, Research Centre Adolescent Development, Utrecht University; Wilma A. M. Vollebergh, Department of Interdisciplinary Social Sciences, Utrecht University; Hans M. Koot, Department of Developmental Psychology, VU University Amsterdam, and EMGO Institute for Health and Care Research; Jaap J. A. Denissen, Department of Developmental Psychology, Tilburg University; Wim H. J. Meeus,
Research Centre Adolescent Development, Utrecht University, and Department of Psychology, Tilburg University.

Data of the RADAR study were used. RADAR has been financially supported by main grants from the Netherlands Organisation for Scientific Research (GBMAGW 480-03-005), and Stichting Achmea Slachtoffer en Samenleving (SASS) to RADAR PI's, and from the Netherlands Organisation for Scientific Research to the Consortium Individual Development (CID; 024.001.003).

Correspondence concerning this article should be addressed to Andrik I. Becht, Research Centre Adolescent Development, Utrecht University, P.O. Box 80 140, 3508 TC Utrecht, the Netherlands. E-mail: a.i.becht@uu.nl 
However, both daily levels and day-to-day fluctuations appear to be essential aspects to tap into certainty and uncertainty dynamics of daily identity formation (Klimstra, Luyckx, Hale, Frijns, van Lier, \& Meeus, 2010a). Experiencing identity uncertainty is assumed to be part of the process of identity commitment making in which adolescents experiment and "try on identities" (Erikson, 1968). Erikson (1968) considered an identity crisis as a normative developmental task of adolescents aimed at forming a stable sense of self. However, it remains to be empirically tested to what extent adolescents show individual differences (i.e., heterogeneity) in the amount and developmental change in daily certainty and uncertainty during identity formation across adolescence. This knowledge may advance our understanding to what extent adolescents' identity crisis can indeed be considered part of normative identity development and identify those adolescents with successful identity formation as well as adolescents having more difficulties in forming their identity. In the present study, we investigated heterogeneity in the development of certainty and uncertainty using an intensive longitudinal design, focusing on daily identity formation across adolescence.

\section{A Process Model of Daily Identity Formation}

Focusing on the process of identity formation, adolescents are assumed to enter adolescence with a set of commitments in salient ideological and interpersonal identity domains that are often based on parental values and norms (Crocetti, Rubini, \& Meeus, 2008). Supporting this assumption that adolescents do not start the identity formation process with a "blank slate" (Meeus, 2011; Meeus et al., 2010), early adolescents have already been found to possess certain identity commitments (Archer, 1982; Meeus et al., 1999). In adolescence, these commitments are however challenged and adolescents' identity formation is considered to take place in a dynamic between identity synthesis (or identity certainty) versus role confusion (or identity uncertainty; Erikson, 1968). In the more recent Meeus-Crocetti model (Crocetti et al., 2008; Meeus et al., 2010), these aspects of identity formation are captured within two dimensions (i.e., commitment and reconsideration of commitment) in which adolescents form identity commitments through a process of choosing commitments and reconsidering them.

The Meeus-Crocetti model has been proven a useful framework to capture the iterative process of construction and revision of adolescents' identity formation on a daily basis (Klimstra et al., 2010a; Schwartz et al., 2011). To measure the process of identity formation, we used the Utrecht-Management Scale (U-MICS; Crocetti et al., 2008). The U-MICS can be considered an extension of Marcia's model of identity, which focused on exploration before commitments are made. Instead, the U-MICS uses dimensions of identification with commitments and reconsidering current identity commitments. The U-MICS is different from Marcia's model (Marcia, 1966) by having a stronger process orientation. In line with a key principal of life span developmental science that shortterm variability is the driving force behind long-term development (Nesselroade \& Molenaar, 2010), long-term identity development is assumed to result from short-term identity processes (Bosma \& Kunnen, 2001; Lichtwarck-Aschoff et al., 2008). Because identity is defined as a self-organizing system operating on a daily basis (Kunnen, Bosma, Van Halen, \& Van der Meulen, 2001), a short- term approach is needed for an in-depth study of identity formation processes (Lichtwarck-Aschoff et al., 2008).

Additionally, the use of daily diary measures of identity allows for the assessment of different aspects of certainty and uncertainty in identity formation. For example, daily levels of identity commitments reflect adolescents' attempts to develop and maintain a stable identity, thereby tapping into short-term aspects of certainty in the identity formation process. Contrary, daily levels of reconsideration represent adolescents' uncertainty in identity formation, where adolescents compare present commitments with alternative ones. While levels of identity dimensions of commitment and reconsideration from the Meeus-Crocetti model tap into the certainty and uncertainty dynamics of identity formation, respectively, day-to-day changes in identity commitment and reconsideration may be considered additional aspects of certainty and uncertainty. For example, day-to-day fluctuations of reconsideration have been found to predict subsequent lower levels of commitment, which suggests that more day-to-day variability may be predictive of a less certain identity later on (Klimstra et al., 2010a; Schwartz et al., 2011). Considering Erikson's (1968) perspective on identity formation, some identity uncertainty is not necessarily negative, but might help adolescents to consider alternative identity commitments and develop a stronger identity over time. However, it remains unclear to what extent adolescents differ from each other in the amount and developmental changes in certainty and uncertainty dynamics of identity formation across adolescence. We will examine heterogeneity in how levels of, and fluctuations in commitment and reconsideration in daily identity formation jointly develop across adolescence as well as associations with concurrent psychosocial adjustment

\section{Heterogeneity in Certainty and Uncertainty Dynamics in Identity Formation Across Two Identity Domains}

Supporting the view that the process of identity formation is not the same for all adolescents (e.g., Marcia, 1966; Meeus et al., 2010; van Hoof, 1999), previous research using annual assessments of identity has shown individual differences in both levels and rate of change in identity commitment and reconsideration from early to late adolescence (Klimstra, Hale, Raaijmakers, Branje, \& Meeus, 2010b; Meeus, Van de Schoot, Keijsers, \& Branje, 2012). In addition, research on identity statuses has consistently found that there are groups of adolescents characterized by a more certain identity (e.g., adolescents with an identity achievement status) as well as groups marked by a more uncertain identity (e.g., adolescents in the identity moratorium status; Luyckx, Schwartz, Goossens, Soenens, \& Beyers, 2008; Meeus et al., 2012).

While theoretically adolescents appear to differ in identity formation processes, it could be expected that experiencing identity uncertainty is part of adolescents' normative identity development (Erikson, 1968). Empirical confirmation of this hypothesis is based on identity status research. According to these studies, around $20 \%-30 \%$ of adolescents are in identity moratorium status during adolescence. However, previous research has also identified adolescents with a stable and certain identity across adolescence (Kroger et al., 2010; Luyckx et al., 2008; Meeus et al., 2012). Yet, most of these studies investigated identity formation with relatively large intervals (e.g., annual identity assessment). Therefore, 
it remains unclear whether some adolescents might experience short-term identity uncertainty or a longer period of identity uncertainty during adolescence. Hence, a microlevel approach to study identity across several years allows investigating in more detail how identity formation processes unfold on a day-to-day basis across adolescence. In doing so, the current study is able to investigate whether there are subgroups of adolescents that differ in the amount and/or developmental change in certainty and uncertainty in daily identity formation across adolescence. By using daily reports, we are able to study identity formation as a process that operates on a daily basis (Kunnen et al., 2001).

Based on the theoretical assumption that identity formation occurs through a dynamic between certainty and uncertainty (Erikson, 1968) and the finding of individual differences between adolescents in identity formation (Klimstra et al., 2010a; Kroger et al., 2010; Luyckx et al., 2008; Meeus et al., 2012; van Hoof, 1999), adolescents may also be expected to differ in the joint development of certainty and uncertainty in the identity formation process on a daily basis. Focusing on daily changes in identity may help to investigate to what extent experiencing an identity crisis is part of adolescents' everyday life, as hypothesized by Erikson (1968). Based on previous research, we expect that many adolescents experience an identity crisis during adolescence (e.g., Luyckx et al., 2008; Marcia, 1966; Meeus et al., 2012). This crisis might be reflected by a pattern of loosening of old commitments, increasing reconsideration and fluctuations regarding their commitments. In contrast, we also expect to find adolescents showing a stable and certain identity across adolescence as reflected by a developmental profile of strong commitments and low reconsideration and commitment fluctuations across adolescence.

At the same time, developmental profiles of certainty and uncertainty of identity formation may also differ across different identity domains. It has been emphasized to study identity domains that are relevant during a particular chronological period (Erikson, 1968). Using both a narrative identity approach and questionnaires, both ideological (i.e., school) and interpersonal (i.e., friends) identity were found to be salient content domains of adolescents' identity formation (McLean, Yoder, Seyed, \& Greenhoot, 2016). A similar distinction between ideological and interpersonal identity domains has been adopted in other identity measures such as the Identity Status Interview (see Archer \& Waterman, Appendix A, Identity status interview, in Marcia, 1993, pp. 286-287), the Ego-Identity Status (Bennion \& Adams, 1986) and the Ego Identity Process Questionnaire (Balistreri, BuschRossnagel, \& Geisinger, 1995). Moreover, previous research has also suggested that the formation of identity can differ across identity domains, with adolescents displaying differences in the pattern and rate of change across the educational and interpersonal domains (Meeus, Iedema, Helsen, \& Vollebergh, 1999). Both educational and interpersonal identity domains are relevant identity domains during adolescence (McLean et al., 2016). However, adolescents might differ in the timing and extent to which they question their identity depending on the identity domain. These differences in identity formation processes across domains might have to do with the extent to which these domains are open to change (Klimstra et al., 2010a; Meeus et al., 1999). For example, within the Netherlands (the country where the present study was conducted) there are different levels of secondary education, namely, vocational education, higher professional education, and university preparatory education. Within these educational levels, students have to choose a specific curricular profile around age 14-15 years. Thus, especially in early adolescence, adolescents have ample opportunities to question their educational identity. In contrast, changes in their interpersonal identity are much more common across adolescence. Because of these potential differences when adolescents have opportunity to question their identity, the current study will investigate certainty-uncertainty dynamics of daily identity formation in both the educational and interpersonal identity domains (Meeus et al., 1999) across adolescence.

\section{Heterogeneity in Certainty and Uncertainty Dynamics in Identity Formation and Associated Psychosocial Adjustment}

Previous research has suggested that an identity developmental process characterized by high uncertainty is related to distress (e.g., Luyckx et al., 2008), which may be expressed in internalizing and externalizing problem behavior (Campbell, 1990; Crocetti et al., 2008; Meeus et al., 1999, 2012; Schwartz et al., 2011). For example, adolescents with lower levels of commitment and higher levels of reconsideration revealed higher levels of both internalizing and externalizing problem behavior (Crocetti et al., 2008; Meeus et al., 2012; Schwartz et al., 2011). Based on these earlier linkages between identity development and psychosocial adjustment, we expect that adolescents experiencing much uncertainty in their identity formation on a daily basis may also be at risk for concurrent psychosocial adjustment problems. Hence, this study also aims to examine whether individual differences in daily identity formation processes across different identity domains (i.e., educational and interpersonal) are associated with the development of internalizing and externalizing behavior across adolescence.

In addition to links between heterogeneity in identity formation processes across domains with general aspects of psychosocial functioning, such as global internalizing and externalizing behavior, identity formation in different domains has also been associated with domain-specific aspects of psychosocial functioning salient to the adolescent period. For instance, daily diary reports on educational identity commitments and reconsideration of commitments have been related to school adjustment, whereas interpersonal identity commitments and reconsideration of commitments have been related to relationship quality with the best friend (Klimstra et al., 2010a). This suggests that identity formation in the educational and interpersonal domains may be expected to be differentially associated with aspects of psychosocial adjustment. To explore this issue, the present study will investigate if individual differences in certainty-uncertainty dynamics of identity formation across the education and interpersonal domains are, potentially differentially, associated with the development of school adjustment and relationship quality with the best friend across adolescence.

\section{The Present Study}

The first aim of the current study was to investigate heterogeneity in developmental profiles of certainty and uncertainty in identity formation from early to late adolescence in the educational and interpersonal identity domains, using an intensive longitudinal 
design across 5 years. Theoretically, we expected a substantial group of adolescents to experience identity uncertainty, as hypothesized to be part of adolescents' normative identity development (Erikson, 1968). These adolescents are expected to show decreasing strength in their commitments, increasing reconsideration and increasing identity fluctuations. In addition, based on previous research, we hypothesized to find a group of adolescents with a more certain and stable identity formation process (i.e., strong commitments, low reconsideration, and low identity fluctuations) across adolescence (e.g., Luyckx et al., 2008; Marcia, 1966; Meeus et al., 2012). Thus, we expected to find two developmental profiles in both the educational and interpersonal identity domains.

Our second aim was to examine how individual differences in certainty-uncertainty dynamics were associated with the development of internalizing (i.e., global anxiety) and externalizing (i.e., aggression) problem behavior. Specifically, we expected to find that adolescents with developmental profiles characterized by high and stable uncertainty in identity formation would also show higher levels of internalizing and externalizing problem behavior over time (e.g., Meeus et al., 2012). Related to this issue, we examined potential differential associations between certaintyuncertainty developmental profiles in the educational and interpersonal identity domains and domain-specific aspects of psychosocial functioning, namely school adjustment and peer relationship quality. We hypothesized that more uncertain developmental profiles of educational identity would be specifically associated with concurrent levels of school anxiety, whereas more uncertain developmental profiles of interpersonal identity would be specifically associated with concurrent levels of best friend relationship quality (Klimstra et al., 2010a).

\section{Method}

\section{Participants}

Participants were 497 Dutch adolescents, part of the young cohort of the ongoing longitudinal project Research on Adolescent Development and Relationships (RADAR-Y). These adolescents were drawn from a large cohort that was assessed before this actual study was initiated. Specifically, all 6th grade elementary school classes in the province of Utrecht, and in the cities of Amsterdam, Rotterdam, The Hague and Almere were invited to participate (e.g., Schwartz et al., 2011). Of the 850 primary education schools in these areas, 429 were randomly selected. There were 296 schools that agreed to participate. For logistic reasons data was collected at 230 schools. Of the 1,544 adolescents who were randomly selected from the participating schools, 497 adolescents met the inclusion criteria for the RADAR-young project (i.e., living with both of their parents, had at least one sibling who was 10 years of age or older at the onset of the study). Three adolescents were dropped from the analyses, because they reported not to attend school anymore at a certain point during the study, because of this, these adolescents could not report on their educational identity. This resulted in a final sample of 494 adolescents $(56.7 \%$ boys) with a mean age of 13.03 years $(S D=0.45$, range $11.01-$ 14.86 years) at the start of the study. Based on parents' job level, most adolescents came from medium to high socioeconomic status (SES) families $(87.9 \%)$.
Sample attrition was low across all 5 years, with $80.8 \%$ of adolescents participating in the first year still participating in the fifth year. No significant differences were found with regard to distribution of boys and girls between adolescents that dropped out over the course of the study compared with adolescents that were still participating, $\chi^{2}(1)=0.53, p=.47, \varphi=.03$. However, adolescents who dropped out across the study were more likely to come from lower SES families, $\chi^{2}(1)=10.45, p=.001, \varphi=.15$, and be slightly older, $t(491)=-3.67, p<.001, d=0.44$.

\section{Procedure}

The present study uses data from the first six waves of RADAR-Y, ages 13-18. Over the course of 5 successive years, adolescents participated in 15 measurement weeks ( 3 online assessment weeks in each of the 5 years, separated by a 3-month interval). Each measurement week, participants filled out an online questionnaire tapping into their identity formation for 5 days in a row (i.e., Monday through Friday), resulting in 75 assessment days. The initial Internet assessment week (T1) took place in June, the second assessment (T2) took place 3 months later in September and T3 took place in December, thus having 3-month intervals in between each assessment week. The first assessment week of the second year (i.e., T4) took place again in June, resulting in a 6-month interval between T3 (December) and T4 (June). This same assessment interval was used across 5 years. To complete the online assessments, participants had to $\log$ on to a website of the RADAR-Y study. Adolescents received $€ 10$ (equivalent to approximately US \$11) for participation in every online assessment week. Adolescents further reported across six annual assessment waves to measure their psychosocial adjustment. The first annual assessment took place 3 months before the first online assessment. All participants signed an informed consent form and the responsible medical ethics committee has approved the RADAR study.

\section{Measures}

Daily identity. Adolescents reported on their identity on a daily basis during the 15 online assessment weeks with a one-item version of the U-MICS (Klimstra et al., 2010a). This version of the U-MICS measures identity on a 5-point Likert scale $(1=\mathrm{com}$ pletely untrue, $5=$ completely true) using one item per identity dimension (i.e., commitment and reconsideration) in the educational (i.e., school) and interpersonal (i.e., relation with best friend) domain. The item for commitment was: "Today, I felt confident about myself because of my school/best friend" (educational/ interpersonal commitment) and for reconsideration: "Today, I felt that I could better look for a different school/best friend" (educational/interpersonal reconsideration). Previous research using the same dataset has shown good validity of the single item version of the U-MICS (Becht et al., 2016; Klimstra et al., 2010a; Schwartz et al., 2011) and validity (Klimstra et al., 2010a), as well as longitudinal measurement invariance (Becht et al., 2016). There is ample empirical support that the full U-MICS questionnaire measures adolescents' identity. For instance, the factor structure has been supported across different samples in different countries (Crocetti et al., 2015). Moreover, the U-MICS scores have been found to be meaningfully related to other identity measures such as 
the Ego Identity Process Questionnaire-Short form (Zimmermann et al., 2012), and related to a range of adolescents' adjustment outcomes (e.g., Crocetti et al., 2008).

Anxiety. Anxiety symptoms were measured with the 38-item Dutch version of Screen for Child Anxiety Related Emotional Disorders across six annual waves (SCARED; Birmaher et al., 1997; Hale, Raaijmakers, Muris, \& Meeus, 2005). Adolescents rated items such as "When frightened, I feel dizzy" and "I worry about going to school" on a 3 -point Likert scale $(1=$ never, $3=$ often). Studies have shown that the SCARED is a reliable and valid instrument to assess adolescent anxiety (e.g., Birmaher et al., 1997; Hale et al., 2005), including school anxiety (Crocetti, Hale, Fermani, Raaijmakers, \& Meeus, 2009). A total anxiety score was created based on all 38 items. Furthermore, a school anxiety score was created based on the corresponding 4-item subscale of the SCARED. Internal consistency of the total anxiety scale was good with Cronbach's $\alpha$ s ranging between 0.91 and 0.94 . Internal consistency of the school anxiety subscale was acceptable across waves with Cronbach's $\alpha$ s ranging between 0.58 and 0.64 across waves.

Aggression. Adolescents' aggression was measured across six annual waves, using 19 items of the Dutch version of the Youth Self Report (YSR; Verhulst, Van der Ende, \& Koot, 1997). Items (e.g., "I argue a lot") were rated on a 3-point Likert scale $(0=$ never, 2 = often). Many studies support the reliability and validity of the YSR, including the aggression subscale of the YSR (Ivanova et al., 2007). Internal consistency was good with Cronbach's $\alpha$ s ranging between 0.84 and 0.88 across the study years.

Best friend relationship quality. Adolescents rated their perceived support from their best friend on the 8-item support subscale of the shortened version of the Network of Relationships Inventory across six annual waves (Furman \& Buhrmester, 1985). Adolescents rated questions such as "How much does your best friend care about you?" on a 5-point Likert scale (ranging from $1=$ little or none, $5=$ the most). Internal consistency was good with Cronbach's $\alpha$ ranging between 0.84 and 0.87 across study waves.

\section{Statistical Analyses}

Our statistical analyses consisted of four successive steps. First, for every online assessment week we computed a weekly mean level score and fluctuation score for commitment and reconsideration in the educational and interpersonal domains separately. Fluctuation scores were based on individuals' within-person standard deviation score per week (Kernis, Grannemann, \& Barclay, 1989; Klimstra et al., 2010a). This first analysis step resulted in 15 week scores for every participant for each variable (i.e., commitment and reconsideration) in each domain (i.e., educational and interpersonal), which were used in further analysis. ${ }^{1}$

Second, we investigated the number and shape of developmental trajectories of certainty (i.e., commitment levels) and uncertainty (i.e., fluctuation in commitment levels and reconsideration) in identity formation across adolescence using multivariate Latent Class Growth Analyses (LCGA). This procedure examines whether there are subgroups with distinct development of the weekly mean level commitment and fluctuation scores across time. The weekly commitment and reconsideration scores were sepa- rated by a 3-month interval within each year, whereas assessment weeks were separated by a 6-month interval between years. To account for these different intervals in our estimation of linear and quadratic change we defined the slope loadings as $0.0,0.1,0.2$, $0.4,0.5,0.6,0.8,0.9,0.10,0.12,0.13,0.14,0.16,0.17,0.18$, which were squared to model the curvilinear trajectories. LCGA analyses were conducted separately for the educational and interpersonal identity domains. To determine the number of latent classes, we used the Bayesian Information Criterion (BIC) and the LoMendell-Rubin adjusted Likelihood Ratio Test (aLRT; Lo, Mendell, \& Rubin, 2001). A lower BIC value indicates a better fitting model and a significant aLRT indicates that a model with $k$ classes fits better than a model with $k-1$ classes. Furthermore, entropy, a measure of qualification certainty, should be acceptable. Entropy values range between 0 and 1 , with values of 0.75 or higher indicating good classification (Reinecke, 2006). In addition, every class had to cover at least $10 \%$ of the sample for meaningful interpretation and subsequent analyses. Finally, we considered interpretability of the classes. For example, a model with one extra class may increase model fit but may result in small class sizes, which may be too small to be meaningful or difficult to replicate (Muthén \& Muthén, 2000).

In the third step, we investigated whether adolescents with different developmental trajectories of certainty and uncertainty in identity formation showed different concurrent psychosocial adjustment. To this end, a series of Latent Growth Models (LGMs) were conducted to examine associations between the different distinguished classes for educational and interpersonal identity and their development of anxiety, aggressive behavior, school anxiety, and adolescent-perceived support from their best friend across 6 years. Specifically, we used the continuous class probabilities from the LCGA analyses and correlated these class probabilities with the growth parameters (i.e., intercept and slopes) of the different forms of psychosocial adjustment in these LGMs, to take classification inaccuracy of participants into the different identity profiles into account. Because of known gender differences in levels of psychosocial adjustment (Leadbeater Kuperminc, Blatt, \& Hertzog, 1999) and higher levels of adjustment problems in lower SES families (Keiley, Bates, Dodge, \& Pettit, 2000), we controlled for these potential differences in all of our LGM analyses. Model fit was assessed with the comparative fit index (CFI) and the root mean squared error of approximation (RMSEA), using conventional standards (Kline, 2013). The Satorra-Bentler scaled $\chi^{2}$ difference test (Satorra \& Bentler, 2001) was used for comparison of different

\footnotetext{
${ }^{1}$ Exploratory multivariate latent growth analyses revealed that the latent growth factors (i.e., intercepts and slopes) of reconsideration level and reconsideration fluctuation were highly positively correlated in both the educational and interpersonal identity domain (all $r \mathrm{~s}>.81$, all $p \mathrm{~s}<.001$ ). Therefore, we examined whether the two-factor structure of reconsideration level and reconsideration fluctuation best represented a one-factor model. Results suggested that a one-factor model of reconsideration did not show significant deterioration of model fit compared with the two-factor model for both educational identity $(\Delta \mathrm{CFI}=0.01, \Delta \mathrm{RMSEA}=0.003)$ and interpersonal identity $(\Delta \mathrm{CFI}=0.01, \Delta \mathrm{RMSEA}=0.002)$. Therefore, we decided to standardize and sum the reconsideration level and reconsideration fluctuation scores and use this combined score of reconsideration level and fluctuation in the LCGA analyses. Additional information is available from the first author upon request.
} 
Table 1

Parameter Estimates of Intercept and Slope Factors of Latent Classes for Educational Identity and Interpersonal Identity

\begin{tabular}{|c|c|c|c|c|c|c|c|c|}
\hline \multirow[b]{3}{*}{ Parameter estimates } & \multicolumn{4}{|c|}{ Educational identity } & \multicolumn{4}{|c|}{ Interpersonal identity } \\
\hline & \multicolumn{2}{|c|}{$\begin{array}{c}\text { Identity } \\
\text { synthesis class } \\
(49 \%)\end{array}$} & \multicolumn{2}{|c|}{$\begin{array}{l}\text { Crisis-like } \\
\text { identity class } \\
(51 \%)\end{array}$} & \multicolumn{2}{|c|}{$\begin{array}{c}\text { Identity } \\
\text { synthesis class } \\
(53 \%)\end{array}$} & \multicolumn{2}{|c|}{$\begin{array}{c}\text { Crisis-like } \\
\text { identity class } \\
(47 \%)\end{array}$} \\
\hline & $M$ & $S E$ & $M$ & $S E$ & $M$ & $S E$ & $M$ & $S E$ \\
\hline \multicolumn{9}{|l|}{ Commitment level } \\
\hline Mean intercept & $3.50^{* * * * *}$ & .05 & $2.74^{* * * *}$ & .05 & $3.30^{\text {***** }}$ & .07 & $2.42^{* * * * *}$ & .10 \\
\hline Mean linear slope & .09 & .09 & $-.51^{* * * *}$ & .11 & .24 & .15 & $-.43^{*}$ & .17 \\
\hline Mean quadratic slope & -.02 & .05 & $.28^{* * * *}$ & .06 & -.13 & .07 & $.18^{*}$ & .09 \\
\hline \multicolumn{9}{|l|}{ Commitment fluctuations } \\
\hline Mean intercept & $.53^{* * * *}$ & .03 & $.63^{* * * * *}$ & .02 & $.50_{\mathrm{a}}^{* * * *}$ & .02 & $.56_{\mathrm{a}}^{* * * *}$ & .03 \\
\hline Mean linear slope & $-.14_{\mathrm{a}}^{*}$ & .05 & $-.15_{\mathrm{a}}^{*}$ & .06 & $-.18_{\mathrm{a}}^{* * *}$ & .05 & $-.066_{\mathrm{a}}$ & .07 \\
\hline Mean quadratic slope & $.04_{\mathrm{a}}^{\mathrm{a}}$ & .03 & $.05_{\mathrm{a}}$ & .03 & $.06^{*}$ & .03 & -.04 & .04 \\
\hline \multicolumn{9}{|l|}{ Reconsideration } \\
\hline Mean intercept & $-.59^{* * * *}$ & .09 & $.58^{* * * *}$ & .11 & $-.42 * * * *$ & .10 & $.46^{* * * *}$ & .14 \\
\hline Mean linear slope & $-.03_{\mathrm{a}}$ & .18 & $.10_{\mathrm{a}}$ & .21 & $-.02_{\mathrm{a}}$ & .21 & $.06_{\mathrm{a}}$ & .30 \\
\hline Mean quadratic slope & $.06_{\mathrm{a}}$ & .09 & $.09 \mathrm{a}$ & .11 & $.02 \mathrm{a}_{\mathrm{a}}$ & .11 & $-.05_{\mathrm{a}}$ & .16 \\
\hline
\end{tabular}

Note. Means with the same subscript do not differ significantly from one another. Thus, means without a subscript also differ significantly from one another. Note that the subscripts apply to each growth function in each identity domain separately (e.g., differences between mean intercepts of commitment level of the two educational identity classes). All $p \mathrm{~s}<.05$.

${ }^{*} p<.05 .^{* *} p<.01 .^{* * * *} p<.001$.

models with different growth factors (i.e., linear and quadratic growth). The aforementioned LCGA and LGM analyses were conducted in Mplus version 7.3 using corrections for nonnormality of the data with the robust MLR estimator (Muthén \& Muthén, 1998-2011). Missing data points on identity scores for each week occurred for $19.91 \%$ of adolescents' assessments across the study. Little's MCAR test revealed that the pattern of missing values could be considered at random with a normed chi-square $(\chi 2 / d f)$ of 1.15 , indicating that it is unlikely that our findings were biased as a result of missing values. Because we found support for MCAR in our sample, we chose to use all available data points per participant by including all of them in the analyses. Full information Likelihood (FIML) was used for our main analyses.

\section{Results}

\section{Heterogeneity in Certainty and Uncertainty Dynamics in Identity Formation Across Two Identity Domains}

Our first aim was to examine the number and shape of developmental trajectories of certainty and uncertainty dynamics in identity formation across adolescence. ${ }^{2}$ We modeled multivariate latent classes based on adolescent commitment levels, fluctuations in commitment levels, and reconsideration over 15 measurement waves (assessed over five successive years) in LCGA analyses for the educational and interpersonal domains of identity separately. Because some adolescents had not reported on their identity, 485 participants could be included in the LCGA analyses for the educational identity domain and 477 participants were included in the analyses for the interpersonal identity domain. ${ }^{3}$
Educational identity trajectories. For educational identity, results suggested that a two-class solution showed the best fit to the data $(\mathrm{BIC}=44,733$, aLRT $p<.001$, entropy $=.89)$, as the BIC for this solution was substantially lower than the one-class solution $(\mathrm{BIC}=47,159)$. Although the BIC suggested that a three-class solution showed an even better fit to the data $(\mathrm{BIC}=$ $44,011)$ the aLRT showed a nonsignificant improvement for a three-class solution $(p=.45)$. The estimated trajectories of certainty and uncertainty in the final two-class solution are presented in Figure 1 and the exact parameter estimates of the intercept and slope factors of the latent classes can be found in Table 1.

Adolescents in the first trajectory class (49\%) showed: (a) relatively high and stable commitment levels, (b) relatively low and decreasing commitment fluctuations, and (c) low stable reconsideration. This class was labeled the educational identity synthesis class. The second trajectory class $(51 \%)$ consisted of adolescents showing: (a) relatively low levels of commitment that decreased from early adolescence onward but increased again after mid-adolescence, (b) decreasing commitment fluctuations, and (c) the highest and stable reconsideration across adolescence. Hence, this class was labeled the crisis-like educational identity class.

\footnotetext{
${ }^{2}$ Because of space constraints, means and correlations of the study variables are not reported here but can be obtained from the first author upon request.

${ }^{3}$ We investigated gender differences in the prevalence in developmental trajectories of identity classes. No significant gender differences were found for educational identity, $\chi^{2}(1)=0.03, p=.86, \varphi=.01$, and interpersonal identity classes, $\chi^{2}(1)=3.52, p=.06, \varphi=.09$.
} 


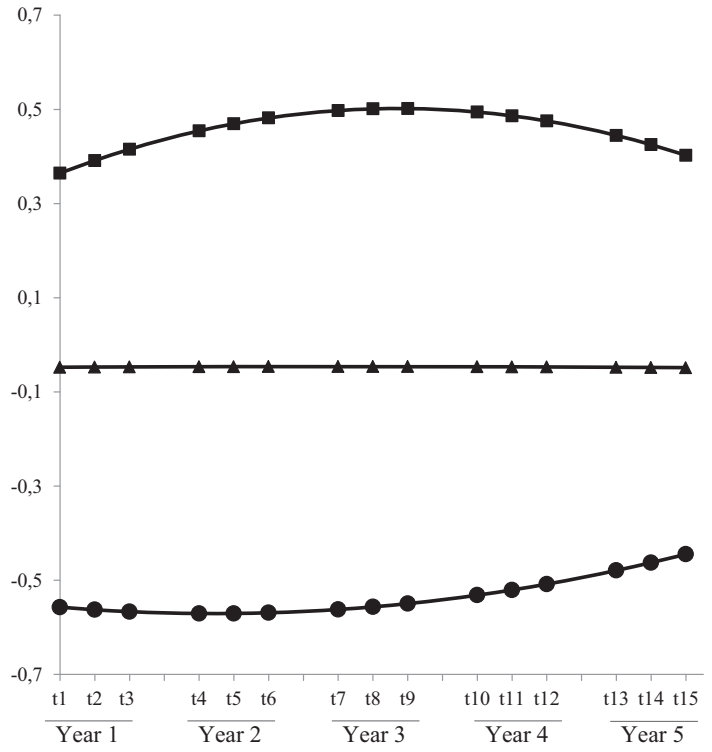

Educational Identity Synthesis Class $(n=238)$

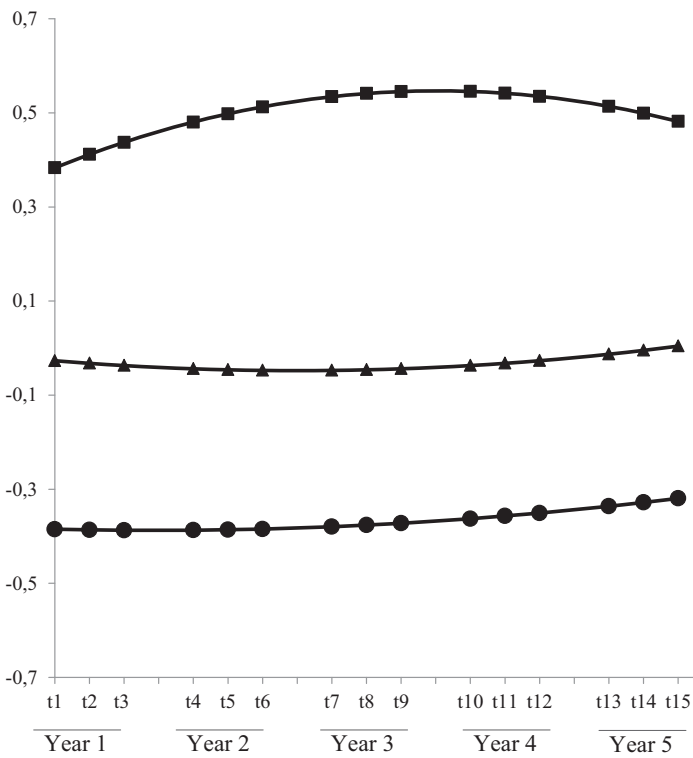

Interpersonal Identity Synthesis Class $(\mathrm{n}=\mathbf{2 5 3})$

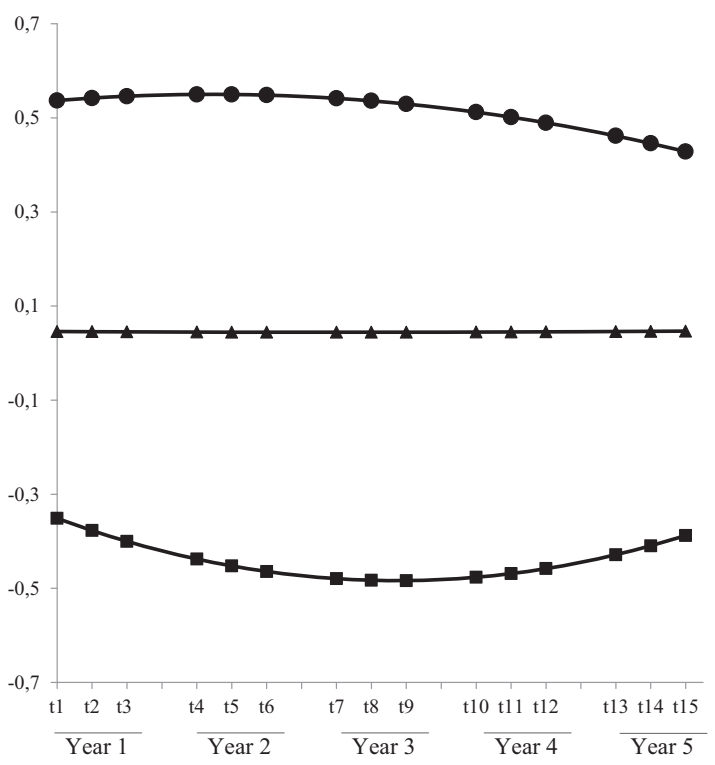

Educational Identity Crisis-Like Class $(n=247)$

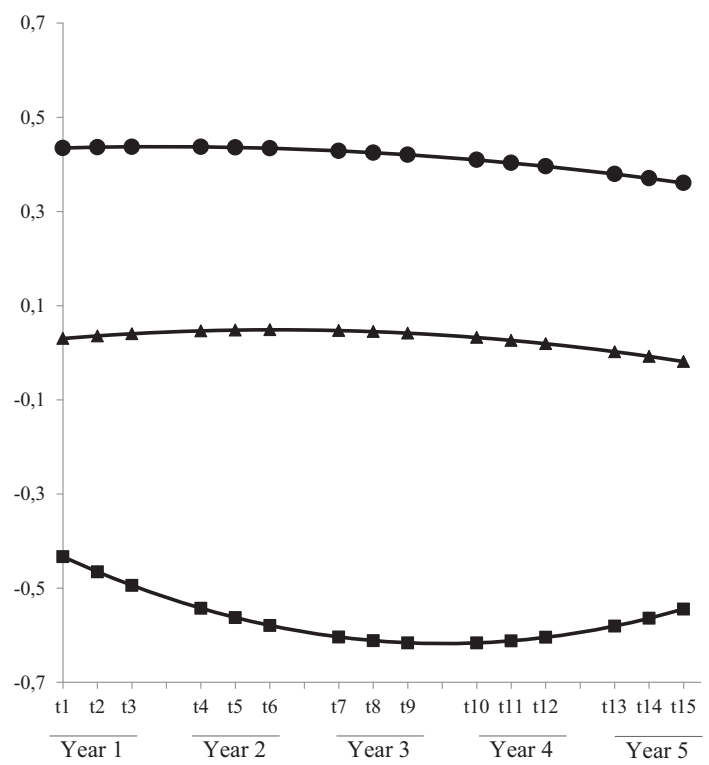

Interpersonal Identity Crisis-Like Class $(n=224)$

Commitment level

Commitment fluctuations

Reconsideration

Figure 1. Estimated trajectories for (top) Educational Commitment Level, Commitment Fluctuation and Reconsideration and (bottom) Interpersonal Commitment Level, Commitment Fluctuation and Reconsideration. Note. For reasons of presentation, the scores of the identity dimensions were centered. The interval between each tic mark is 3 months. Hence, the interval between T3 and T4, for example, is 6 months.

Interpersonal identity trajectories. For interpersonal identity, results indicated a two-class solution $(\mathrm{BIC}=42,945$, aLRT $p=.004$, entropy $=.88$ ), as the BIC for this solution was lower than the one-class solution $(\mathrm{BIC}=45,213)$. While the BIC suggested that a three-class solution showed a better fit to the data $(\mathrm{BIC}=42,002)$ the aLRT showed a nonsignificant im- 
Table 2

Correlations Between Class Probabilities and Growth Factors for Anxiety, Aggression, School Anxiety, and Support Best Friend

\begin{tabular}{|c|c|c|c|c|c|c|c|c|c|c|c|c|}
\hline \multirow[b]{2}{*}{ Class probability } & \multicolumn{3}{|c|}{ Anxiety } & \multicolumn{3}{|c|}{ Aggression } & \multicolumn{3}{|c|}{ School anxiety } & \multicolumn{3}{|c|}{ Support best friend } \\
\hline & INT. & LS. & QS. & INT. & LS. & QS. & INT. & LS. & QS. & INT. & LS. & QS. \\
\hline \multicolumn{13}{|l|}{ Educational identity } \\
\hline Crisis-like class & $.23^{* * * *}$ & .12 & -.10 & $.23^{* * * *}$ & $.14^{*}$ & $-.17^{*}$ & $.33^{* *}$ & .16 & -.14 & $-.13^{*}$ & -.08 & .08 \\
\hline Interpersonal identity & & & & & & & & & & & & \\
\hline Crisis-like class & $.18^{* * *}$ & -.08 & .07 & $.13^{*}$ & .09 & $-.15^{*}$ & .18 & -.01 & -.01 & $-.16^{*}$ & $-.24^{* * * *}$ & $.2^{* * *}$ \\
\hline
\end{tabular}

Note. $\quad$ INT $=$ intercept $; \mathrm{LS}=$ linear slope $; \mathrm{QS}=$ quadratic slope.

${ }^{*} p<.05 .{ }^{* * *} p<.01 .{ }^{* * * *} p<.001$.

provement for a three-class solution $(p=.053)$. The two-class solution for interpersonal identity is presented in Figure 1 and parameter estimates are presented in Table 1.

The first trajectory class (53\%) included adolescents with: (a) relatively high commitment levels in late adolescence, (b) low and decreasing commitment fluctuations, and (c) relatively low reconsideration. This class was labeled the interpersonal identity syntheses class. The second trajectory class (47\%) included adolescents showing: (a) relatively low, and strongly decreasing commitment levels which increased again after mid-adolescence, (b) relatively high and stable commitment fluctuations, and (c) relatively high and stable reconsideration. Hence, this class was labeled the crisis-like interpersonal identity class.

\section{Heterogeneity in Certainty and Uncertainty Dynamics in Identity Formation and Associated Psychosocial Adjustment}

For our second aim, we examined whether developmental trajectories of identity formation across different identity domains predict developmental trajectories of (global and school) anxiety, aggression, and perceived best friend support. All LGMs showed good model fit (CFIs ranged between 0.96 and 1.00 and RMSEAs ranged between 0.00 and 0.06). Because we identified two classes in both identity domains, the identity synthesis classes were used as the reference class in the LGMs. See Table 2 for the correlations between the class probabilities and latent growth factors for aggression, total anxiety, school anxiety and perceived support from the best friend.

Global anxiety. For educational identity, we found that adolescents with a higher probability of belonging to the crisis-like identity class showed a higher intercept of anxiety problems compared with the identity synthesis class. Similarly, a higher class probability of the crisis-like interpersonal identity class was related with a higher intercept on total anxiety problems. In summary, results supported our hypothesis by showing that higher class probabilities of belonging to the crisis-like trajectories of both educational and interpersonal identity were associated with higher levels of global anxiety.

Aggression. Concerning the educational identity domain, results suggested that adolescents with a higher probability of belonging to the crisis-like educational identity class showed higher intercept levels of aggression and a steeper increase and subsequent decrease across adolescence compared to the educational identity synthesis class. Concerning the interpersonal identity domain, class probability of the crisis-like interpersonal identity class was related to a higher intercept of aggression. Thus, in line with our hypothesis, higher class probabilities of belonging to the crisis-like identity classes in both educational and interpersonal identity were associated with higher initial levels and growth of aggression across adolescence.

School anxiety. Next, we investigated whether higher uncertainty in developmental profiles of educational identity but not interpersonal identity would be specifically related to the development of school anxiety. Regarding educational identity, a higher class probability of belonging to the crisis-like identity class was related with a higher intercept of school anxiety compared to the identity synthesis class. Class probabilities of the crisis-like interpersonal identity class were not related with intercept and growth in school anxiety. Thus, consistent with our hypothesis, only the class probabilities of the crisis-like educational identity class were related to the development of school anxiety.

Perceived support best friend. Furthermore, we investigated whether higher uncertainty in developmental profiles of the interpersonal identity domain but not educational identity would be specifically related to the development of perceived support from the best friend. In contrast to our expectations, the class probability of the crisis-like educational identity class was related to a lower intercept of perceived support from the best friend. Consistent with our hypothesis, the class probability of the crisis-like interpersonal identity class was related with a lower intercept, steeper decrease and subsequent increase in perceived support across adolescence. Thus, our hypothesis was partially supported because, contrary to our expectations, the class probability of the crisis-like educational identity class was also related with the development of perceived support from the best friend. However, in line with our hypothesis, the class probability of the crisis-like interpersonal identity class was associated with the development of perceived support.

\section{Discussion}

Results from the present study provide insight into heterogeneity in the development of certainty-uncertainty dynamics of daily identity formation processes across adolescence. Based on levels and developmental change of certainty and uncertainty in identity formation, we identified two distinct developmental profiles of identity formation in the educational domain and two distinct developmental profiles of identity formation in the interpersonal identity domain. Many adolescents showed fairly high levels of identity certainty in identity formation from age 13 to 18 years. However, a comparable amount of adolescents displayed a pattern of identity crisis in their daily identity 
formation over the course of adolescence. This pattern of high identity uncertainty was evidenced by low and strongly decreasing commitment levels, which increased again after middle adolescence, relatively high but decreasing identity fluctuations and stable levels of reconsideration. Adolescents in these crisislike developmental trajectories in both the educational and interpersonal identity domains also showed relatively more general and domain specific psychosocial adjustment problems.

\section{Heterogeneity in Certainty and Uncertainty Dynamics in Identity Formation Across Two Identity Domains}

Consistent with our expectations, we identified different subgroups of adolescents that followed distinct developmental profiles in certainty-uncertainty dynamics of daily identity formation processes. Supporting Erikson's (1968) notion that experiencing an identity crisis is common in adolescence, we were able to identify two subgroups of adolescents following a crisis-like pattern in their daily identity formation. These adolescents in the crisis-like educational identity class (51\%) and the crisis-like interpersonal identity class (47\%) displayed a clear certainty-uncertainty dynamic with a dip in the strength of their commitments in middle adolescence that was joined by relatively high reconsideration of alternative identity commitments. Adolescents following a crisis like pattern of identity formation showed identity distress across early to late adolescence with the strongest period of identity crisis between ages 15 to 17 . These crisis-like subgroups of adolescents appear to show an identity formation process somewhat similar to a state of moratorium, in which adolescents have not made significant commitments and strongly consider different identity commitments (e.g., Marcia, 1966; Meeus et al., 2010). Moreover, our finding that identity crisis peaks in mid-adolescence is in line with earlier work showing that a state of identity moratorium is most prevalent in early to mid-adolescence (Meeus et al., 2012).

Furthermore, our findings suggest that many adolescents do not appear to "grow out" of a pattern of identity uncertainty (Marcia, 1966), as demonstrated by continuing higher levels of uncertainty from early to late adolescence in the two crisis-like identity formation classes. Most previous studies on identity formation did not differentiate between identity domains, but investigated identity formation at a global level by averaging scores across different identity domains. A meta-analyses on these studies showed that across adolescence (ages 13-18 years) between 22 and 37\% of adolescents were in a moratorium identity status (Kroger et al., 2010). These adolescents in moratorium are in the process of exploring identity commitments while having vague commitments. For the purpose of comparison with these studies, we investigated how many adolescents were both in the educational crisis-like class as well as the interpersonal identity crisislike class. Similar to previous studies (Kroger et al., 2010) in our study, $32.8 \%$ of adolescents experienced relatively high identity uncertainty in both the educational and interpersonal identity domains. While exploring identity alternatives and questioning current identity commitments can be considered a key task of adolescents as evidenced by the crisis-like classes in our study (Erikson, 1968), it is important to further study daily identity formation processes during young adulthood. We expect that that some adolescents will grow out of identity uncertainty during the transition to emerging adulthood. However, if adolescents continue to have identity uncertainty during emerging adulthood, this might backfire during a period in which a more stable sense of self is expected. Future studies should investigate whether some adolescents are sensitive to experience persistent identity uncertainty in identity formation across different developmental phases, like the transition to adulthood.

Our results also show that a large proportion of adolescents already feel quite certain about their identity throughout adolescence. For instance, adolescents in the educational identity synthesis class (49\%) showed relatively high levels of commitment throughout adolescence, decreasing commitment fluctuations, and stable low reconsideration. Similarly, adolescents in the interpersonal identity synthesis class $(53 \%)$ showed a pattern of certainty in their identity formation with increasing commitments throughout adolescence, decreasing daily fluctuations in their commitments, and low reconsideration. These findings suggest that a substantial proportion of adolescents showed a pattern of identity maturation toward developing less uncertainty and consolidating their commitments across adolescence.

Consistent with our hypotheses, developmental profiles of certainty and uncertainty in identity formation differed between adolescents. However, we only found limited support for hypothesized differences in identity formation processes across the educational and interpersonal identity domains. That is, in both identity domains, adolescents in the crisis-like identity profiles showed similar decreasing strengths of their commitments and relatively high reconsideration of alternative commitments. However, adolescents in the crisis-like interpersonal identity class did not decrease in their identity fluctuations across adolescence. However, for educational identity adolescents in both the synthesis class and crisis-like class decreased in their fluctuations in identity commitments across adolescence. These findings suggest that some adolescents continue to have uncertainty about their interpersonal identity commitments as reflected in stable identity fluctuations. Indeed, it has been suggested that differences in identity formation across domains are dependent on whether identity formation occurs within open versus more closed identity domains (Meeus et al., 1999). Because friendships are more open to change compared with the educational identity domain, especially during adolescence (Branje, Frijns, Finkenauer, Engels, \& Meeus, 2007), adolescents' interpersonal identity might also be more open to daily fluctuations in the strength of commitments.

Overall, we found that a considerable proportion of adolescents tend to show a pattern of identity uncertainty across adolescence (Erikson, 1968), evidenced by (temporary) decreasing strengths of their current identity commitments and continued consideration of identity alternatives across adolescence. These findings suggest that many adolescents are in a phase of identity experimentation in which their identity is not yet fixed and stable. However, we also identified a substantial number of adolescents that revealed a pattern of identity consolidation toward developing less uncertainty about their daily identity commitments across adolescence (Kroger et al., 2010; Meeus, 2011).

\section{Heterogeneity in Certainty and Uncertainty Dynamics in Identity Formation and Associated Psychosocial Adjustment}

As predicted, we found that individual differences in developmental profiles of identity formation were related to adolescents' adjustment over time. In line with previous research, adolescents 
with relatively high certainty and not so much doubt in their daily identity formation processes showed the most positive psychosocial adjustment across adolescence (Crocetti et al., 2008; Meeus et al., 1999, 2012; Schwartz et al., 2011). Contrary, adolescents following a crisis-like developmental profile of identity formation across adolescence displayed relatively higher initial levels as well as stronger increases in global anxiety and aggression. These findings also support the validity of the identified identity formation classes as adolescents in these classes did also experience somewhat higher psychosocial adjustment problems across adolescence. Although we cannot disentangle the developmental order between identity formation processes and adjustment problems from the current study, previous work has suggested that identity formation processes characterized by high uncertainty contribute to distress (e.g., Luyckx et al., 2008), such as anxiety. Moreover, daily measures of identity reconsideration in early adolescence have been found to predict later anxiety and depression, but not vice versa (Schwartz et al., 2011). Future research is needed to further investigate bidirectional processes between certainty and uncertainty processes of identity formation and adjustment problems across adolescence.

In addition to links between identity formation processes and associations with development in general psychosocial adjustment domains, like anxiety and aggression, we also found support for differential associations between identity formation processes in specific identity domains and domain-specific psychosocial adjustment. Specifically, in line with our hypothesis and previous research (Klimstra et al., 2010a), a crisis-like identity formation profile in the educational identity domain was related with higher initial levels of school anxiety. These results support earlier work that adolescents with a more uncertain and immature identity profile relates to lower adjustment (Meeus, 2011). Importantly, the crisis-like interpersonal identity formation profile was not associated with school anxiety.

Moreover, in line with our domain-specific hypothesis, the crisis-like interpersonal identity formation profile was only related to psychosocial adjustment in the interpersonal domain as reflected by a steep decrease in perceived support from their best friend from early to middle adolescence and a subsequent increase in perceived support near the end of adolescence. However, in contrast with our hypothesis, adolescents in the crisis-like educational identity class also reported less perceived support from their best friend, suggesting that feeling uncertain about your educational identity may partially generalize to other areas of psychosocial functioning. These results further support the importance of differentiating between different identity domains when studying identity formation and associated development of psychosocial adjustment, as both more general and more domain-specific associations appear to exist. Hence, the current study further supports the finding that identity may operate differently across different content domains (Goossens, 2001).

According to Erikson (1968), uncertainty about identity is part of adolescence everyday life. Consistent with this notion, we found indeed that a substantial proportion of adolescents showed a pattern of identity uncertainty in adolescence. Moreover, we found that adolescents' experiencing identity distress were at risk of concurrent adjustment problems during adolescence. These findings confirm that identity formation can be a stressful task for many adolescents. More important, however, this does not mean that all adolescents continue to experience an identity crisis during the transition to adulthood. We propose a multifinality developmental principle on identity formation. A multifinality principle suggests that a similar experience should not necessarily lead to the same outcome for all adolescents. For example, adolescents may begin with a similar experience of identity distress but develop very different patterns of identity formation over time. We believe that the principle of multifinality may also apply to identity formation processes. That is, having an identity crisis in adolescence may forecast adjustment problems for some, but not all adolescents when transitioning to adulthood (Cicchetti \& Rogosch, 2002). Future studies should investigate daily identity formation patterns across adolescence and young adulthood to further investigate which adolescents continue to experience an identity crisis beyond adolescence.

\section{Strengths, Limitations, and Future Directions}

The current study has several important strengths. First, our intensive longitudinal design including daily identity reports that were assessed across five successive years enabled us to investigate microlevel processes in identity development covering the entire period of adolescence. Second, the current study was able to use a relatively large sample as well as many repeated measures, which increases statistical precision of our estimated models as well as increasing statistical power (Muthén \& Curran, 1997). Third, we were able to investigate aspects of certainty and uncertainty in identity formation more in depth by including both levels and fluctuations in our study in two important domains of adolescent identity formation (i.e., educational and interpersonal). Fourth, we were able to support the theoretical validity of the identified identity formation classes by showing that different developmental profiles of identity formation were associated with the development in other areas of psychosocial adjustment.

In addition to these strengths, some limitations need to be addressed. A first limitation concerns the descriptive nature of this study. We did not investigate mechanisms of change in identity formation, or, for example, why some adolescents show a crisislike developmental pattern in identity development. Obviously, adolescents' daily identity formation does not develop in a social vacuum but in interaction with the social environment. For example, the period of adolescence and emerging adulthood are marked by many life transitions such as changes from school to work and the formation of intimate relationships. Future daily diary studies that focus on the link between daily identity formation and life transitions could further inform us about the role of short-term changes in identity formation and life transitions.

A second limitation of this study concerns the lack of a measure aimed to measure cultural differences in our sample. The Netherlands can be considered a western society that emphasizes independent self construal rather than interdependent self-construal. However, within Italian families, for example, there is less focus on individual choice and less push to greater independence. Instead, there is more focus on familial togetherness and there are lower expectations to make an early transition to adulthood. These cultural difference might explain why Italian adolescents were found to experience more and longer periods of uncertainty regarding their personal identity formation compared with Dutch adolescents (Crocetti, Schwartz, Fermani, Klimstra, \& Meeus, 
2012). Similarly, Turkish adolescents were found to have higher levels of identity uncertainty compared with adolescents in the Netherlands (Morsunbul, Crocetti, Cok, \& Meeus, 2016). These findings suggest the importance to further study cultural differences in daily identity formation processes within diverse cultural contexts.

Third, the current study does not allow drawing any conclusions on the direction of effects between different aspects of identity formation. While the current study showed differences between adolescents in their identity formation processes on a daily basis, future research is needed to study predictors and consequences of daily identity formation processes. Fourth, in our statistical models, growth factors of reconsideration level and fluctuation were highly positively correlated. Therefore, distinguishing between these two variables was deemed unnecessary in the current study. However, future research with different research questions and statistical analyses may further investigate both levels and fluctuations of reconsideration. Fifth, the community sample included primarily Dutch adolescents from relatively high SES families, which raises questions to what extent our findings can be replicated to adolescents from different socioeconomic backgrounds. Finally, while the current study covered an important developmental period of adolescence, the period of transitioning to adulthood is substantially prolonged for many Western nations (Arnett, 2014), which also imposes many challenges to the development of a stable identity because of the extended phase of exploring and preparing for adult roles (Schwartz, Côté, \& Arnett, 2005). Future research is needed to investigate how daily identity formation processes develop during the transition from adolescence into adulthood.

Despite these limitations, this study contributed significantly to our understanding of heterogeneity in daily identity formation across adolescence. Focusing on daily identity, our findings support Erikson's (1968) hypothesis that many adolescents experience an identity crisis during adolescence, which may have ramifications for their concurrent behavioral and emotional development.

\section{References}

Archer, S. (1982). The lower age boundaries of identity development. Child Development, 53, 1551-1556. http://dx.doi.org/10.2307/1130083 Arnett, J. J. (2014). Emerging adulthood: The winding road from the late teens through the twenties. Oxford: Oxford University Press. http://dx .doi.org/10.1093/acprof:oso/9780199929382.001.0001

Balistreri, E., Busch-Rossnagel, N. A., \& Geisinger, K. F. (1995). Development and preliminary validation of the Ego Identity Process Questionnaire. Journal of Adolescence, 18, 179-192. http://dx.doi.org/10 $.1006 /$ jado.1995.1012

Becht, A. I., Branje, S. J., Vollebergh, W. A., Maciejewski, D. F., van Lier, P. A., Koot, H. M., . . Meeus, W. H. (2016). Assessment of identity during adolescence using daily diary methods: Measurement invariance across time and sex. Psychological Assessment, 28, 660-672.

Bennion, L. D., \& Adams, G. R. (1986). A revision of the extended version of the objective measure of ego identity status: An identity instrument for use with late adolescents. Journal of Adolescent Research, 1, 183197. http://dx.doi.org/10.1177/074355488612005

Birmaher, B., Khetarpal, S., Brent, D., Cully, M., Balach, L., Kaufman, J., \& Neer, S. M. (1997). The screen for child anxiety related emotional disorders (SCARED): Scale construction and psychometric characteristics. Journal of the American Academy of Child \& Adolescent Psychi- atry, 36, 545-553. http://dx.doi.org/10.1097/00004583-19970400000018

Bosma, H. A., \& Kunnen, E. S. (2001). Determinants and mechanisms in ego identity development: A review and synthesis. Developmental Review, 21, 39-66. http://dx.doi.org/10.1006/drev.2000.0514

Branje, S. J., Frijns, T., Finkenauer, C., Engels, R., \& Meeus, W. (2007). You are my best friend: Commitment and stability in adolescents' same-sex friendships. Personal Relationships, 14, 587-603. http://dx .doi.org/10.1111/j.1475-6811.2007.00173.x

Campbell, J. D. (1990). Self-esteem and clarity of the self-concept. Journal of Personality and Social Psychology, 59, 538-549. http://dx.doi.org/10 $.1037 / 0022-3514.59 .3 .538$

Cicchetti, D., \& Rogosch, F. A. (2002). A developmental psychopathology perspective on adolescence. Journal of Consulting and Clinical Psychology, 70, 6-20. http://dx.doi.org/10.1037//0022-006X.70.1.6

Crocetti, E., Cieciuch, J., Gao, C. H., Klimstra, T., Lin, C. L., Matos, P. M., ... Meeus, W. (2015). National and Gender Measurement Invariance of the Utrecht-Management of Identity Commitments Scale (U-MICS): A 10-Nation study with university students. Assessment, 22, 753-768. http://dx.doi.org/10.1177/1073191115584969

Crocetti, E., Hale, W. W., III, Fermani, A., Raaijmakers, Q., \& Meeus, W. (2009). Psychometric properties of the Screen for Child Anxiety Related Emotional Disorders (SCARED) in the general Italian adolescent population: A validation and a comparison between Italy and the Netherlands. Journal of Anxiety Disorders, 23, 824-829. http://dx.doi.org/10 .1016/j.janxdis.2009.04.003

Crocetti, E., Rubini, M., \& Meeus, W. (2008). Capturing the dynamics of identity formation in various ethnic groups: Development and validation of a three-dimensional model. Journal of Adolescence, 31, 207-222. http://dx.doi.org/10.1016/j.adolescence.2007.09.002

Crocetti, E., Schwartz, S. J., Fermani, A., Klimstra, T., \& Meeus, W. (2012). A cross-national study of identity status in Dutch and Italian Adolescents. European Psychologist, 17, 171-181. http://dx.doi.org/10 .1027/1016-9040/a000076

Erikson, E. (1968). Youth: Identity and crisis. New York, NY: Norton. http://dx.doi.org/10.1126/science.161.3838.257

Furman, W., \& Buhrmester, D. (1985). Children's perceptions of the personal relationships in their social networks. Developmental Psychology, 21, 1016-1024. http://dx.doi.org/10.1037/0012-1649.21.6.1016

Goossens, L. (2001). Global versus domain-specific statuses in identity research: A comparison of two self-report measures. Journal of Adolescence, 24, 681-699. http://dx.doi.org/10.1006/jado.2001.0438

Hale, W. W., III, Raaijmakers, Q., Muris, P., \& Meeus, W. (2005). Psychometric properties of the screen for child anxiety related emotional disorders (SCARED) in the general adolescent population. Journal of the American Academy of Child \& Adolescent Psychiatry, 44, 283-290. http://dx.doi.org/10.1097/00004583-200503000-00013

Ivanova, M. Y., Achenbach, T. M., Rescorla, L. A., Dumenci, L., Almqvist, F., Bilenberg, N., . . Verhulst, F. C. (2007). The generalizability of the Youth Self-Report syndrome structure in 23 societies. Journal of Consulting and Clinical Psychology, 75, 729-738. http://dx .doi.org/10.1037/0022-006X.75.5.729

Keiley, M. K., Bates, J. E., Dodge, K. A., \& Pettit, G. S. (2000). A cross-domain growth analysis: Externalizing and internalizing behaviors during 8 years of childhood. Journal of Abnormal Child Psychology, 28, 161-179. http://link.springer.com/article/10.1023/A:1005122814723. http://dx.doi.org/10.1023/A:1005122814723

Kernis, M. H., Grannemann, B. D., \& Barclay, L. C. (1989). Stability and level of self-esteem as predictors of anger arousal and hostility. Journal of Personality and Social Psychology, 56, 1013-1022. http://dx.doi.org/ 10.1037/0022-3514.56.6.1013

Klimstra, T. A., Hale, W. W., III, Raaijmakers, Q. A., Branje, S. J., \& Meeus, W. H. (2010b). Identity formation in adolescence: Change or 
stability? Journal of Youth and Adolescence, 39, 150-162. http://dx.doi .org/10.1007/s10964-009-9401-4

Klimstra, T. A., Luyckx, K., Hale, W. A., III, Frijns, T., van Lier, P. A., \& Meeus, W. H. J. (2010a). Short-term fluctuations in identity: Introducing a micro-level approach to identity formation. Journal of Personality and Social Psychology, 99, 191-202. http://dx.doi.org/10.1037/a0019584

Kline, R. B. (2013). Principles and practice of structural equation modeling. 2005. New York, NY: Guilford Press.

Kroger, J., Martinussen, M., \& Marcia, J. E. (2010). Identity status change during adolescence and young adulthood: A meta-analysis. Journal of Adolescence, 33, 683-698. http://dx.doi.org/10.1016/j.adolescence.2009 .11 .002

Kunnen, E. S., Bosma, H. A., Van Halen, C. P. M., \& Van der Meulen, M. (2001). A self-organizational approach to identity and emotions: An overview and implications. In H. A. Bosma \& E. S. Kunnen (Eds.), Identity and emotion (pp. 202-230). Cambridge, England: Cambridge University Press. http://dx.doi.org/10.1017/CBO9780511598425.017

Leadbeater, B. J., Kuperminc, G. P., Blatt, S. J., \& Hertzog, C. (1999). A multivariate model of gender differences in adolescents' internalizing and externalizing problems. Developmental Psychology, 35, 1268-1282. http://dx.doi.org/10.1037/0012-1649.35.5.1268

Lichtwarck-Aschoff, A., van Geert, P., Bosma, H., \& Kunnen, S. (2008). Time and identity: A framework for research and theory formation. Developmental Review, 28, 370-400. http://dx.doi.org/10.1016/j.dr .2008.04.001

Lo, Y., Mendell, N., \& Rubin, D. (2001). Testing the number of components in a normal mixture. Biometrika, 88, 767-778. http://dx.doi.org/ 10.1093/biomet/88.3.767

Luyckx, K., Goossens, L., \& Soenens, B. (2006). A developmental contextual perspective on identity construction in emerging adulthood: Change dynamics in commitment formation and commitment evaluation. Developmental Psychology, 42, 366-380. http://dx.doi.org/10 $.1037 / 0012-1649.42 .2 .366$

Luyckx, K., Schwartz, S. J., Goossens, L., Soenens, B., \& Beyers, W. (2008). Developmental typologies of identity formation and adjustment in female emerging adults: A latent class growth analysis approach. Journal of Research on Adolescence, 18, 595-619. http://dx.doi.org/10 $.1111 / \mathrm{j} .1532-7795.2008 .00573 . \mathrm{x}$

Marcia, J. E. (1966). Development and validation of ego-identity status. Journal of Personality and Social Psychology, 3, 551-558. http://dx.doi .org/10.1037/h0023281

Marcia, J. E. (1993). The ego identity status approach to ego identity. In J. E. Marcia, A. S. Waterman, D. R. Matteson, S. L. Archer, \& J. L. Orlofsky (Eds.), Ego identity: A handbook for psychosocial research (pp. 3-21). New York, NY: Springer-Verlag. http://dx.doi.org/10.1007/ 978-1-4613-8330-7

McLean, K. C., Syed, M., Yoder, A., \& Greenhoot, A. F. (2016). The role of domain content in understanding identity development processes. Journal of Research on Adolescence, 26, 60-75. http://dx.doi.org/10 $.1111 /$ jora. 12169

Meeus, W. (2011). The study of adolescent identity formation 2000-2010: A review of longitudinal research. Journal of Research on Adolescence, 21, 75-94. http://dx.doi.org/10.1111/j.1532-7795.2010.00716.x

Meeus, W., Iedema, J., Helsen, M., \& Vollebergh, W. (1999). Patterns of adolescent identity development: Review of literature and longitudinal analysis. Developmental Review, 19, 419-461. http://dx.doi .org/10.1006/drev.1999.0483

Meeus, W., van de Schoot, R., Keijsers, L., \& Branje, S. (2012). Identity statuses as developmental trajectories: A five-wave longitudinal study in early-to-middle and middle-to-late adolescents. Journal of Youth and
Adolescence, 41, 1008-1021. http://dx.doi.org/10.1007/s10964-0119730-y

Meeus, W., van de Schoot, R., Keijsers, L., Schwartz, S. J., \& Branje, S. (2010). On the progression and stability of adolescent identity formation: A five-wave longitudinal study in early-to-middle and middle-to-late adolescence. Child Development, 81, 1565-1581. http://dx.doi.org/10 $.1111 / \mathrm{j} .1467-8624.2010 .01492 . x$

Morsunbul, U., Crocetti, E., Cok, F., \& Meeus, W. (2016). Identity statuses and psychosocial functioning in Turkish youth: A person-centered approach. Journal of Adolescence, 47, 145-155. http://dx.doi.org/10.1016/ j.adolescence.2015.09.001

Muthén, B. O., \& Curran, P. J. (1997). General longitudinal modeling of individual differences in experimental designs: A latent variable framework for analysis and power estimation. Psychological Methods, 2, 371-402. http://dx.doi.org/10.1037/1082-989X.2.4.371

Muthén, L. K., \& Muthén, B. O. (1998-2012). Mplus user's guide: Seventh edition. Los Angeles, CA: Author.

Muthén, B., \& Muthén, L. K. (2000). Integrating person-centered and variable-centered analyses: Growth mixture modeling with latent trajectory classes. Alcoholism: Clinical and Experimental Research, 24, 882891. http://dx.doi.org/10.1111/j.1530-0277.2000.tb02070.x

Nesselroade, J. R., \& Molenaar, P. C. M. (2010). Emphasizing intraindividual variability in the study of development over the life span: Concepts and issues. In W. F. Overton \& R. M. Lerner (Eds.), The handbook of lifespan development: Volume 1: Cognition, biology, and methods (pp. 30-54). Hoboken, NJ: Wiley. http://dx.doi.org/10.1002/ 9780470880166.hlsd001002

Reinecke, J. (2006). Longitudinal analysis of adolescents' deviant and delinquent behavior. Methodology, 2, 100-112. http://dx.doi.org/10 $.1027 / 1614-2241.2 .3 .100$

Satorra, A., \& Bentler, P. M. (2001). A scaled difference chi-square test statistic for moment structure analysis. Psychometrika, 66, 507-514 http://dx.doi.org/10.1007/BF02296192

Schwartz, S. J., Côté, J. E., \& Arnett, J. J. (2005). Identity and agency in emerging adulthood two developmental routes in the individualization process. Youth \& Society, 37, 201-229. http://dx.doi.org/10.1177/ $0044118 X 05275965$

Schwartz, S. J., Klimstra, T. A., Luyckx, K., Hale, W. W., III, Frijns, T., Oosterwegel, A., . . . Meeus, W. H. J. (2011). Daily dynamics of personal identity and self-concept clarity. European Journal of Personality, 25, 373-385. http://dx.doi.org/10.1002/per.798

van Hoof, A. (1999). The identity status field re-reviewed: An update of unresolved and neglected issues with a view on some alternative approaches. Developmental Review, 19, 497-556. http://dx.doi.org/10 $.1006 /$ drev.1999.0484

Verhulst, F. C., van der Ende, J., \& Koot, H. M. (1997). Handleiding voor de CBCL/4-18 [Manual for the CBCL/4-18]. Rotterdam, the Netherlands: Erasmus University and Department of Child and Adolescent Psychiatry, Sophia Children's Hospital.

Zimmermann, G., Mahaim, E. B., Mantzouranis, G., Genoud, P. A., \& Crocetti, E. (2012). Brief report: The Identity Style Inventory (ISI-3) and the Utrecht-Management of Identity Commitments Scale (U-MICS) Factor structure, reliability, and convergent validity in French-speaking university students. Journal of Adolescence, 35, 461-465. http://dx.doi .org/10.1016/j.adolescence.2010.11.013

Received December 1, 2015

Revision received September 14, 2016

Accepted September 15, 2016 